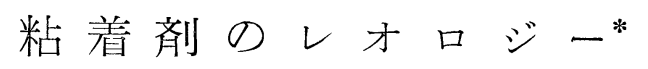

鎌 形一夫** 遠山三夫林

\title{
The Rheological Properties of Pressure Sensitive Adhesives
}

by

\author{
Kazuo Kamagata and Mitsuo Toyama \\ (Development Department, Nichiban Co., Ltd., Tokyo)
}

\begin{abstract}
Hereunder is reported the study made of the rheological properties of pressure-sensitive adhesives by measurement of viscosity, Young's modulus, compliance and relaxation modulus, and the discussion made of the relationship between the rheological properties and the tackiness.

The adhesive systems are blends of masticated natural rubber and the pentaerythritol ester of partially hydrogenated rosin.

It is known from observations with an electron microscope and measurements of mechanical loss that the compositions containing no less than $40 \mathrm{wt}-\%$ resin are homogeneous mixtures, and when the resin concentration exceeds $40 \mathrm{wt}-\%$, the phase separation occurs and the disperse phase is resin containing a small amount of rubber.

The tackiness measured with probe tack tester for a short contact time $(0.2 \mathrm{sec})$ takes the maximum value at the $60 \mathrm{wt}-\%$ resin concentration and for a longer contact time $(2-20 \mathrm{sec})$ takes the maximum value at the $70 \mathrm{wt}-\%$.

While the viscosity and Young's modulus, measured at $20^{\circ} \mathrm{C}$, takes the minimum value at the $70 \mathrm{wt}-\%$ resin concentration, the instantaneous compliance takes the maximum value at the 60 $\mathrm{wt}-\%$ and the steady-state compliance takes the maximum value at the $70 \mathrm{wt}-\%$.

When the wettability of adhesive to the adherent therefore reaches the maximum, the maximum in the tackiness is obtained.

The relationship between the tackiness and relaxation spectrum was also made the subject of our discussion.

(Received Jan. 29, 1972)
\end{abstract}

\section{1 緒言}

粘着剤のレオロジ一的研究は主にテープ状試料のは く離によってなされてきた。 don, Kaelble, 烟, 野中, 福沢等の研究があり, マッ クスウェル，フォークトあるいは 3 要素模型を用いて 理論式も導かれて㧍り, 実験值とかなりよく一致する ことが報告されている. しかし, 粘着剤はレオロジー 的には粘弾性液体であり, 被着体との接触時間により, 粘着力は異なる. 接着され, 破壞するまでの過程を結 合過程と破壞過程にわけて考光るならば, 粘着剤のは く離に関する研究は主に破壞過程を, レオロジー的化 取り扱かったものである。この場合には, 完全に接着 されていることが前提条件となっている．わずかな圧 力と時間で接着することを使命とする粘着剤の場合に は, 破壊過程だけでなく, 結合過程拉よび粘着剤自体 のレオロジー的考察が必要である.

* 原稿受理 昭和47年 1 月29日

** 二チバン(株)開発部 東京都練馬区貫井

*** 正会員 ニチバン(株)開発部 東京都練馬区貫井
粘着剤の粘弾性と粘着力との関係については, Kaelble, Dahlquist の実験がある。

著者らは, 一つの典型的な粘着剤として, 素練した 天然ゴムと水添ロジンのペンタェリスリトールェステ ルの混合物を試料として, クリープ, 応力緩和, 動的 損失などを測定し，粘着力との関係を検討した結果に ついて述べる.

\section{2 試料および測定方法}

\section{$2 \cdot 1$ 試料}

エラストマーとしての素練した天然ゴム $\left(\bar{M}_{v}=5.72\right.$ $\left.\times 10^{5}\right)$ と粘着付与剤樹脂としての部分水添ロジンのペ ンタエリスリトールエステル $\left(\bar{M}_{n}=900\right.$, 軟化点 $\left.96^{\circ} \mathrm{C}\right)$ を種々の割合で $n$ 一ヘキサンに溶解し，充分かく捧し て混合した. 粘着力, クリープコンプライアンス測定 用試料はプライマー処理を施したポリエステルフィル ム(ルミラー\#25) に天然ゴム, 樹脂混合溶液を塗布し, nーヘキサンを除去して粘着剤の厚みが $0.05 \pm 0.005$ $\mathrm{mm}$ になるようと作製した。プライマー処理は粘着剂 $\left(\gamma_{c}=30-37 \mathrm{dyne} / \mathrm{cm}\right)$ とポリエステルフィルム $\left(\gamma_{c}=\right.$ 
42-43 dyne $/ \mathrm{cm})^{9)}$ の両方に親和性を有し，かつ凝集力 の高い物質の溶液を塗布することにより行なった。プ ライマー処理したポリエステルフィルムから粘着剤が 被着材の方へ移行しないことを確認してから使用に供 した。

溶剂は粘着剂塗布面をへアードライヤーで熱風を送 り, 乾燥して除去した. さらに, 約 1 週間, 減圧乾燥 して残りの溶剂を除去した。応力緩和, 引張試験用試 料は混合溶液をシリコーン処理したガラス板に流し, nーヘキサンを除去した後，熱プレスで厚みが $0.8 \mathrm{~mm}$ になるようと作製した。 粘度測定用試料はガラス板上 で $n$ ーへキサンを除去したのみのものを用いた，動的 損失測定用試料は混合溶液を口紙飞滲久込ませ， $n$ 一へ キサンを除去したものを用いた。

\section{$2 \cdot 2$ 測定方法}

粘着力の測定はすでに報告した $\stackrel{10)}{10}$ ig. 1 亿示すプロー ブタックテスターを用いて $20^{\circ} \mathrm{C} て ゙$ 行なった。クリープ コンプライアンスの測定はFig. 2 に示す装置で行なっ た．固定したベークライト板に試料を貼りつけ，その 上に接触端子をシアノアクリレート接着剤ではりつけ た試料の下端に分銅を釣下げ，変位を与克，その変位 をストレンダージで検出し，增幅して記録した。応力 緩和実験は $-20^{\circ} \mathrm{C} \sim+60^{\circ} \mathrm{C}$ 亿調整された恒温槽中で一 定ひずみを印加し，応力をストレンゲージで検出し， 增幅して記録した，粘度は高化式フローテスターを用 いて求め, 引張試験はインストロンタイプの引張試験 機 (TOM 30型) で行なった。測定温度は $20^{\circ} \mathrm{C}$, 引張

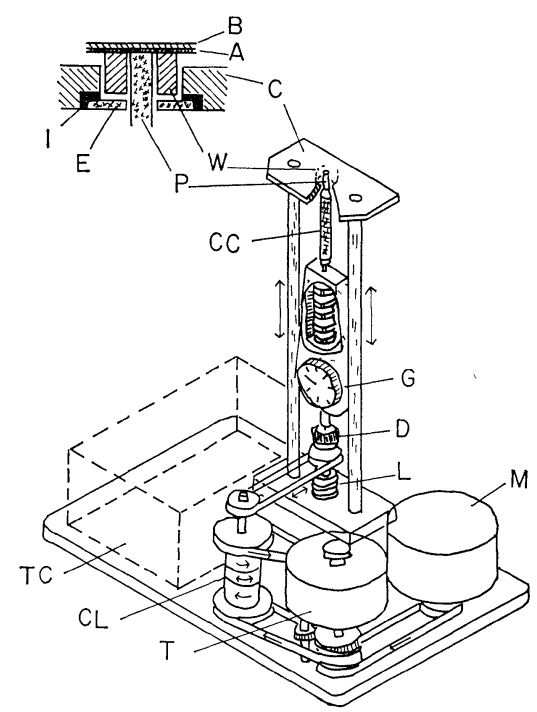

$\mathrm{B}$ : backing, A : adhesive, $\mathrm{W}$ : weight, $\mathrm{P}$ : probe, C: carrier, I : insulation, $E$ : electrical contacts, CC : probe holder, G : gauge, D : dashpot, L : lead screw, $\mathrm{CL}$ : clutches, $\mathrm{T}$ : transmission, $\mathrm{M}$ : motor, TC : time and controls

Fig. 1. Schematic diagram of probe tack tester.

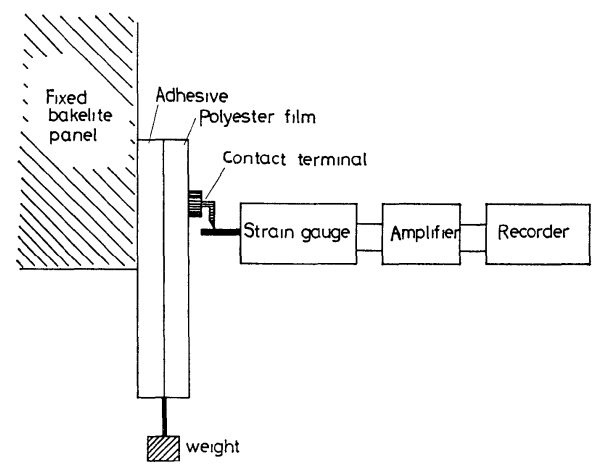

Fig. 2. Schematic diagram of assembly measuring shear creep.

速度は $0.5 \mathrm{~cm} / \mathrm{min}$ で行なった。

\section{3 結果および考察}

天然ゴムと水添ロジンのペンタェリスリトールエス テル混合物についてはすでに報告したように，樹脂量 が $40 \mathrm{wt}$-\%までは均一混合であり，60 wt-\%になると 樹脂を多く含む相が出現することが電子顕微鏡観察よ り明らかとなった。これはFig. 3 亿示した動的損失の 結果からも明らかである。樹脂量が $60 \mathrm{wt}$ \% となる とー42ㄷのピークの他に, $-30^{\circ} \mathrm{C}$ にョルダーがあら われる.この相の状態をモデル的に示したのが Fig. 4 である. Fig. 1 のプローブタックテスターを用いて求 めた粘着力を樹脂量に対してプロットすると Fig. 5 の

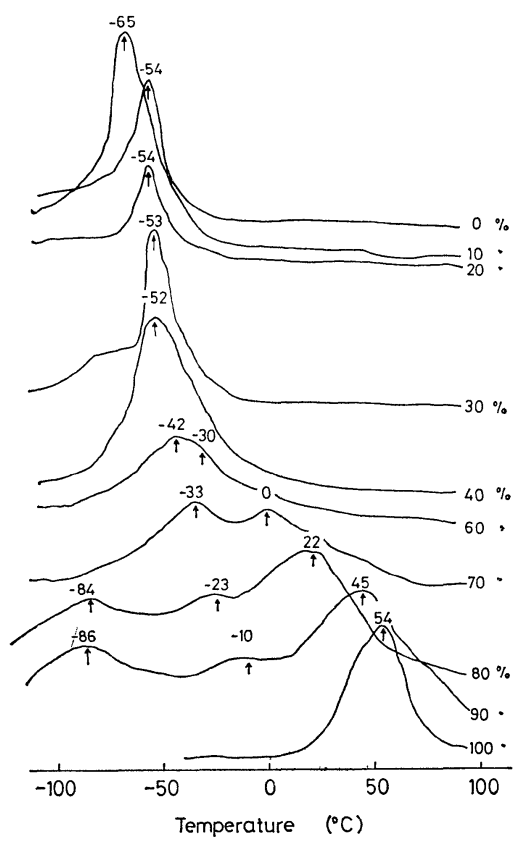

Fig. 3. Temperature dispersion of mechanical loss for blends of natural rubber and the pentaerythritol ester of partially hydrogenated rosin. Percentage figures refer to the concentration in wt$\%$ of resin in each blend. 

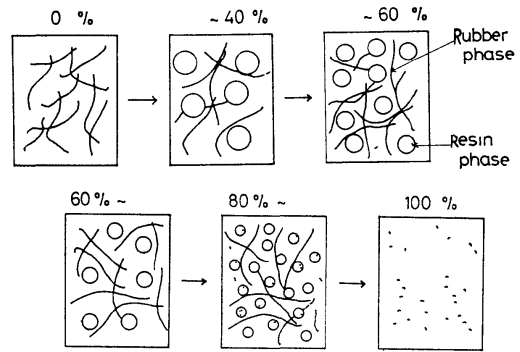

Fig. 4. Schematic representation of structures of blends of rubber and resin.

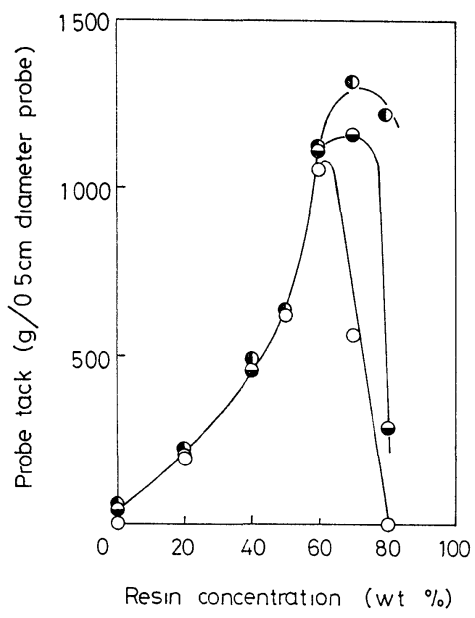

Fig. 5. Probe tack value as function of resin concentration. Contact time: (O) $0.2 \mathrm{sec},(\ominus) 2.0 \mathrm{sec}$, (D) $20 \mathrm{sec}$.

ようになる。接触圧は $100 \mathrm{~g} / \mathrm{cm}^{2}$ であり, 引張速度は $1 \mathrm{~cm} / \mathrm{sec}$ で行なった。接触時間が $0.2 \mathrm{sec}$ の場合に は $60 \mathrm{wt}$-\%で極大となり，2 sec，20 secでは $70 \mathrm{wt}-\%$ で極大となる。

粘着剤の粘度叔よびャング率を示すと Fig. 6,7 のよ うになり，樹脂量 $70 \mathrm{wt}$ \%に極小值を示す。プロー ブタック（粘着力）を結合過程と破壊過程にわけて考 えるならば，結合過程において粘度，ヤング率は低い 方が微視的な意味でのぬれが容易に生じ，ミクロ的に 粗な被着材表面に接近し易くなる。破壊過程に和いて は，はく離が粘着剂層での凝集破壞ならば，粘度，ヤ ング率が高い方が粘着力は高くなるが，以前に報告し たように ${ }^{12)} 1 \mathrm{~cm} / \mathrm{sec}$ の引張速度では可視的には界面 破壊であり, 被着体への密着のよい低粘度, 低弾性率 の方が高い粘着力を示すと考光られる.

プローブタックの場合, 接触時間は一般に短かく, 圧力も $100 \mathrm{~g} / \mathrm{cm}^{2}$ と小さいがこの場合はプローブヘッ ドで粘着剤がどれだけ変形するかをみるために，粘着 剂のクリープニンプライアンスを測定した。

Fig. 2 の方法で求めたクリープ曲線をFig. 8 亿示す. Dahlquist の考察によると, 粘着剤の 1 秒でのコン

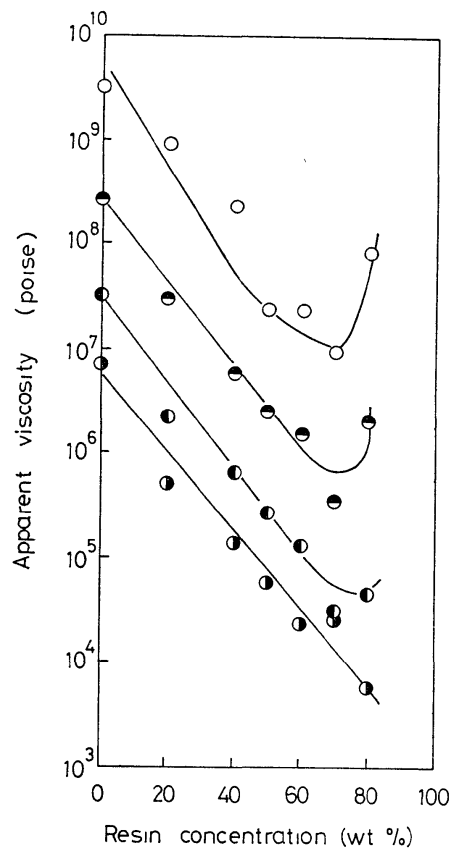

Fig. 6. Relationship between resin concentration and apparent viscosity at various temperature. (O) $20^{\circ} \mathrm{C}$, (-) $40^{\circ} \mathrm{C}$, (D) $60^{\circ} \mathrm{C}$, (() $80^{\circ} \mathrm{C}$.

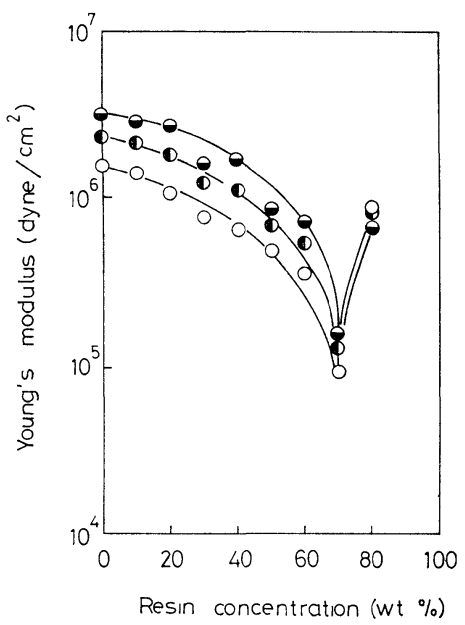

Fig. 7. Relationship between resin concentration and Young's modulus. (O) $50 \%$ elongation, (D) $100 \%$ elongation, (๑) $200 \%$ elongation.

プライアンスを $1 \times 10^{-6} \mathrm{~cm}^{2} /$ dyne とすると, 粘着剤 上に $100 \mathrm{~g} / \mathrm{cm}^{2}\left(\fallingdotseq 10^{5} \mathrm{dyne} / \mathrm{cm}^{2}\right)$ の荷重をかけて圧着 した場合, 粘着剤は 1 秒で約10\%の変形を受ける。1 秒でのコンプライアンスが $1 \times 10^{-7} \mathrm{~cm}^{2} /$ dyne 以下に なると, $10^{5} \mathrm{dyne} / \mathrm{cm}^{2}$ の圧力では粘着剤の変形は小さ くなり，乙たがって粘着力は活とんどなくなる。

よい瞬間粘着性を有する粘着剂は瞬間粘着性のわる い粘着剤よりも非常海かい時間で高いコンプライア ンスを有することになる。 


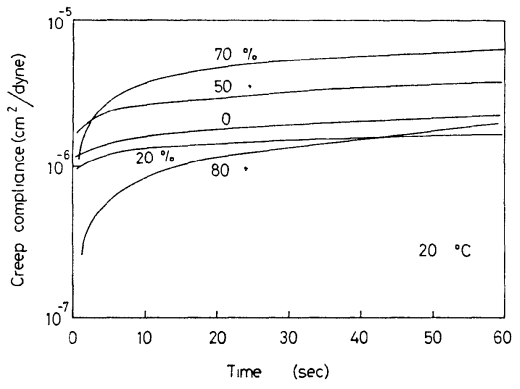

Fig. 8. Creep complance for blends of natural rubber and the pentaerythritol ester of partially hydrogenated rosin. Percentage figures refer to the concentration in wt- $\%$ of resin in each blend.

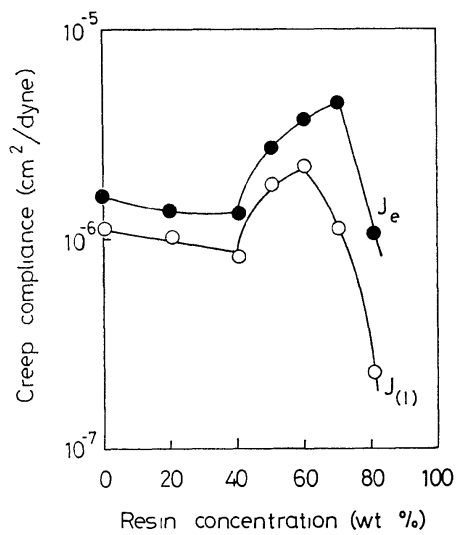

Fig. 9. Relationship between resin concentration and creep compliance. (O) instantaneous compliance, (-) steady-state compliance.

1 秒のコンプライアンスと定常状態コンプライアン スを樹脂濃度に対してプロットするとFig. 9 のように なる。1秒でのコンプライアンスは樹脂量 $60 \mathrm{wt}-\%$ で 極大となり，定常コンプライアンスは 70wt-\%で極大 となる.この結果と Fig. 5 のプローブタックテストの 結果とを比較すると, 接触時間が $0.2 \mathrm{sec}$ のプローブ タックは $60 \mathrm{wt}-\%$ の樹脂量で極大となり，2２0 sec では $70 \mathrm{wt}$-\% で極大となることによく対応している。

接着の初期条件としてのぬれは粘着剂の粘度が低く， コンプライアンスが高い棌ど有利であり，プローブヘ ッドとの接触をよくし，高い粘着力を示す.

粘着剂の被着材への微視的な意味でのぬれを容易に するため粘度を下げるには低分子量のゴムを加えても よいが一般には樹脂を加えた方が粘度が同一の場合に は粘着力は高くなる. 粘着力は本質的には, 被着材を 垂直方向にひっぱった時のプローブの半径方向への粘 着剤の流動に対する抵抗だと考えられるため, 粘性流 動のみかけの活性化エネルギの高いものほど粘着力は 高くなる。

昭和 47 年 5 月

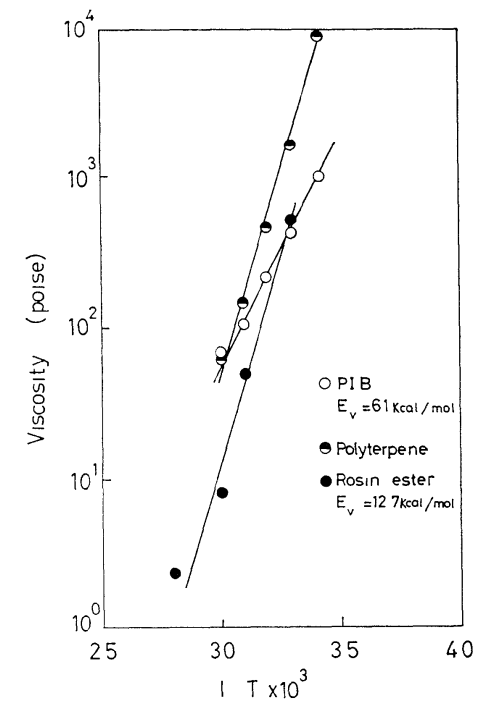

Fig. 10. Arrhenius plots of temperature dependence of resin.

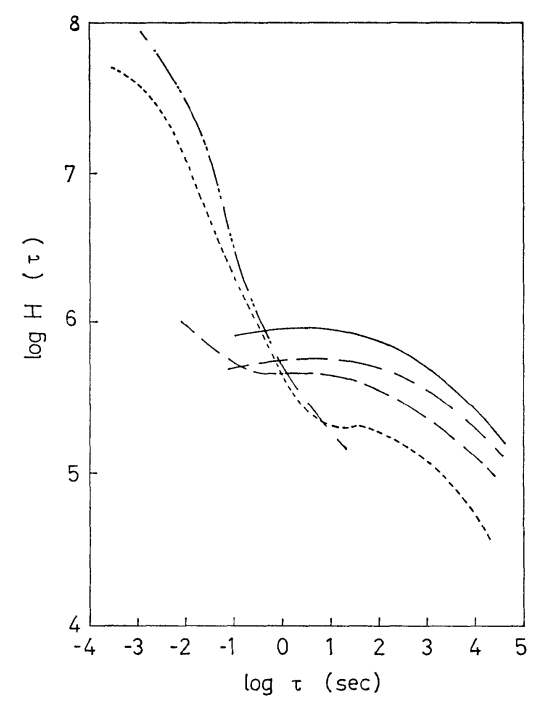

Fig. 11. Relaxation spectra of blends. Resin concentration.

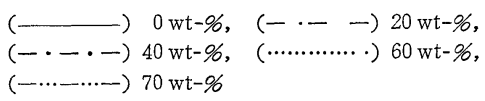

Fig. 10 に低分子量の $\operatorname{PIB}\left(\bar{M}_{n}=1000\right)$, ポリ $(\beta$ ピ ネン) (軟化点 $\left.16.5^{\circ} \mathrm{C}, \bar{M}_{n}=510\right)$ 扎よびロジンのト リエチレングリコールエステル（軟化点 $-3^{\circ} \mathrm{C}, \bar{M}_{n}=$ 510)の粘度のアレニウスプロットを示す。図から明ら かなよらに，樹脂の見かけの活性化エネルギは PIB のそれにくらべて約 2 倍になる，したがって，樹脂の 場合の方が流動に対する抵抗が大きくなり，粘着力は昌 高くなる。

次に, $-20 \sim+60^{\circ} \mathrm{C}$ の温度で測定した緩和弾性率を 時間軸に沿って移動して得た合成緩和曲線から，第一 
次近似で算出した緩和スペクトルを Fig. 11 亿示ず。 そのスペクトルは短時間側は “くさび型”分布, 長時 間側は “箱型”分布で近似できる。樹脂量が増加する と箱型の部分がなくなり，くさび型部分だけとなる。

粘着戍の被着体へのぬれをよくするにはゴム状平坦 領域は低い方がよい。樹脂量が $70 \mathrm{wt}-\%$ の場合には ゴム状領域がほとんどなく，このような場合には接触 時間が短かいと粘着力を示さないようになる。

粘着剂に要求されるもら一つの要因である保持力を よくするには,ゴム状領域の長いもの注どよい。この 図から判断すると，樹脂量 $40 \mathrm{wt}$ - \% の場合がもっと むよい.これは構造的には均一混合状態にある.

複素弾性率と粘着力との関係を論じた Dahlquist の 実駼結果は著者らの結果とまったく逆で西り, 粘着力 の極大を示す樹脂量のところで複素弾性率が極大とな る.しかし，詳細な実験データがないため，充分な議 論はできない。

(昭和46年10月19日第19回レオロジー討㻅会にて講演)

\section{参 考 文 献}

1) Gardon, J. L., J. Appl Polym. Sc1, 7, 643 (1963).

2) Kaelble, D.H., Trans. Soc. Rheol., 3, 161 (1959); 4, 45 (1960); 9, 2, 135 (1965).

3) 畑 敏雄, 材料, 13, 341 (1964).

4) 野中保雄, J. Adhesion 1, 180 (1969).

5）福沢敬司，日本接着協会誌， 5, 294 (1969).

6) Kaelble, D. H., J.Adhesion 1, 102 (1969).

7) Dahlquist, C. A., "Adhesion, Fundamentals and Practice” p. 143 (1966) Ed. D. D. Eley, Maclaren and Sons Ltd, London

8）鎌形一夫, 小坂英夫, 比野欣之輔, 遠山三夫, J. Appl. Polym. Sc1., 14, 2039 (1970).

9）遠山三夫, 北崎寧昭, 渡辺 愛, 日本接着協会誌, 6 , 356 (1970).

10）鎌形一夫, 斎藤次雄, 遠山三夫, 日本接着協会誌, 5 , 364 (1969); J. Adhesion 2, 279 (1970).

11）鎌形一夫, 小坂英夫, 遠山三夫, 日本接着協会誌, 7 , 332 (1971).

12）神戸博太郎, 鎌形一夫, 日本接着協会誌, 4, 224 (1968); J. Appl. Polym. Sc1., 13, 493 (1969).

(391頁より)

79. Characterization of NBR networks from stress-strain and swelling equilibrium measurements, A. M. Hassan, L. N. Ray, Jr, 1837.

80. The influence of chemical structure on the dynamic properties of sulfur-vulcanized carbon blackreinforced natural rubber, G. M. Doyle, R. E. Humphreys, R. M. Russell, 1855.

81. Bead-spring model of dilute polymer solutions : Continuum modifications and explicit constitutive equation, R. J. Gordon, A. E. Everage, Jr., 1903.

82. Influence of hysteresis on tensile and fatigue failure in rubbers, A. R. Payne, R. E. Whittaker, 1941.

83. Viscous behavior of some liquid rubber resins, Y.Peyser, J. M. Dealy, M. R. Kamal, 1963.

84. Rheology of concentrated suspensions, J. S. Chong, E. B. Christiansen, A. D. Baer, 2007.

85. Craze relaxation: A rapid and simple method for glass transition temperature determination in amorphous polymers, G. Salee, 2049.

86. Some aspects of PVC paste rheology, G. Butters, G. Roberts, 2357.

87. Viscoelastic properties of epoxy resin. I. Effect of prepolymer structure on viscoelastic properties, N. Hata, J. Kumanotani, 2371.

88. Energy adsorption in polymeric forms. II. Prediction of impact behavior from Instron data for foams with rate-dependent modulus, D. M. Schwaber, E. A. Meinecke, 2381.

89. Rheological and heat transfer aspects of the melt spinning of monofilament fibers of polyethylene and polystyrene, D. Acierno, J, N, Dalton, J. M. Rodriguez, J.L. White, 2395.

90. Properties of poly (alkylene oxide) elastomers, H. L. Hsieh, R.F. Wright, 2417.

91. The secondary relaxation process of poly(vinyl chloride) and its derivatives, V. Heidingsfeld, J. Zelinger, V. Kuška, 2447.

92. Chemorheological study of vulcanized rubbers under mechanical stress, T. Kusano, Y. Suzuki, K. Murakami, 2453.

93. Unidirectional fiber-polymer composites: Swelling and modulus anisotropy, A. Y. Coran, K. Boustany, P. Hamed, 2471.

(400頁へ) 